the possibility of effective treatment of cerebral palsied children with extreme pessimism ' and recalls the pioneer workers in this field of not so long ago in this country and America. Apart from the sociological interest of current trends in the Soviet Union towards the handicapped child what does this book add to our way of thinking and understanding the problems of cerebral palsy? Their appeal for the management of the child as a whole person rather than the treatment of the affected separate part of the body will find warm support here. But most outstanding and impressive is their report of the use of Galanthamine, an alkaloid with powerful anti-cholinesterase properties, at present only obtainable from Bulgaria! It followed the use of Neostigmine in a variety of different neurological disorders. They ascribe its effect to its ' de-inhibitory effects on nervous tissue' and after its successful use in myesthenia gravis, myopathy and syringomyelia they used it on children with cerebral palsy. However sceptical this book may make the reader feel it is certainly very evocative and thought provoking. It is well printed on good paper and with good layout. Allowing for the unavoidable effects of an otherwise very readable translation and allowing for all the fundamental basic differences in outlook and orientation the publishers are to be commended for breaking down barriers by publishing this book. A month in the Soviet Union experiencing at first hand their pædiatric services enabled me to read this book with a patronizing tolerance.

\section{Biotherapy of Malignant Tumours}

N. G. Klyuyeva and G. I. Roskin. Translated from the Russian by J. J. Oliver and edited by W. J. P. Neish. Pp. iv +3 I 4, illustrated. Oxford, London, New York and Paris: Pergamon Press. I963. 8os.

This book, translated from the Russian, is a fairly readable and interesting account of original work done during the last 25 years by the authors at Moscow University. The work is concerned almost entirely with the investigation into the properties of a substance 'Cruzin' or 'Trypanosa' obtained from cultures of Trypanosoma cruzi, the protozoon responsible for Chaga's disease.

Only the first and relatively short part of the book deals with the general problem of cancer ' biotherapy'. However, it contains a brief history and some interesting references to the use of various substances derived from living organisms, which have been used against cancer. This began in 1894 with Coley's fluids or toxins, and proceeds up to the present via azaserine and the actinomycins.

The main part is concerned with the clinical effects of the trypanosome derived substance on human cancer - mainly lip and breast. The method of production is not given but it is administered intramuscularly every day for 2-3 months or even longer, depending on the response. The case histories are given in full only for those patients surviving recurrence-free at five years: 79 black and white photographs accompany the case histories but unfortunately many of these are of rather poor quality. Precise statistics of the treated cases are not provided, but the results are obviously inferior to orthodox therapy by surgery and radiotherapy. Nevertheless, the evidence in this book shows that regression of tumours can occur with this preparation. The most remarkable clinical property of this agent compared with other cancer chemotherapeutic agents is its apparent harmlessness to normal tissues. Blood counts quoted show no change during a course of injections. Despite this observation there seemed to be an optimum dose (although this varies with each patient) above which further benefit was not observed.

Later chapters on serial histology and animal work suggest that this substance is selectively taken up by tumour cells and that it acts by making malignant cells less virulent so that they can be dealt with by body defence mechanisms. There are numerous plates of degenerating malignant cells and infiltrating macrophages.

In clinical practice we gain little from this book which will help us to treat cancer more effectively, but it is worth reading for the discussions and references. We shall have to await further work, in particular controlled trials, before we can finally assess the place of the trypanosome preparation in cancer therapy.

\section{An Atlas of Electrocardiography}

Hugo Roesler, M.D., F.A.C.P. and Evan Fletcher, M.D., M.R.C.P. Pp. vii +700 , illustrated. Bristol : John Wright. 1963. £7. 7s.

This new book on electrocardiography consists of tracings from 400 patients, arranged as far as possible under diagnoses, and extensively annotated. The authors believe (and none will contradict them) that knowledge of clinical electrocardiography can only be acquired 'by the critical analysis of a large number of of tracings correlated with clinical and pathological data', and they consider the book will be of most value to those already familiar with the elements of the subject. This then is not a textbook, but rather a collection of E.C.G.s illuminated by case histories. Each figure has its accompanying interpretation-a detailed description of the complexes in the various leads-followed by the E.C.G. diagnosis, clinical data and comments. Autopsy findings are given in a third of the cases. Though the section titles guide the reader to some extent, the absence of headings to each figure makes quick reference difficult and compels close study of tracing and text-perhaps the authors' intention. The analysis is very thorough and there are no short cuts for the reader, so that the study of even a few tracings demands considerable application. The section on ischæmic heart disease rightly forms a large portion of the book, and the correlation with autopsy findings is of great value here. There are instructive examples, among other topics, of ventricular hypertrophy, pericarditis, emphysema and the arrhythmias. The vectorial interpretation of tracings is freely employed-a commendable step in this country where 'pattern electrocardiography' still holds sway-and there are useful observations on the terminal vector changes in myocardial infarction. The tracings have been selected with care and are' of good quality, though a number of them have been reduced too much in size for easy inspection. Apart from a short introductory paragraph at the head of each section there is no general exposition, and no references are given. The 'comment' accompanying each tracing is used to summarize the lesson and draw the necessary conclusions.

This work avowedly sets out to teach by weight of example rather than by extraction of principle. The authors are right in their belief that analysis of many tracings is the best way to master the subject. But it is a truism of medical practice that second-hand case histories are never as interesting as one's own (who is not prone to not skip them in.the journals ) - a fact which may diminish the appeal of this expensive book to readers with abundant clinical material of their own. For these the first search for guidance would normally be in one of the conventional textbooks of electrocardiography where fact and principle can be found, supported maybe by illustrations. The present work, consisting entirely of illustrations, does not lend itself to 
use in this way, but it contains none the less a wealth of information and is the fruit of much care and labour. Provided its purpose is understood it will be found a stimulating addition to the E.C.G. library.

\section{Creative Minds in Medicine}

William Carleton Gibson, D.Phil.(oXon.), M.D.C.M., Professor of the History of Medicine and Science, University of British Columbia, Vancouver, Canada. Pp. xi +238 , illustrated. Springfield, Illinois: Charles C Thomas. I963. \$6.75.

The last half-century has indeed been remarkable for the great advances in scientific medicine and surgery, advances which our distinguished forbears could scarcely have envisaged. The study of the history of medicine has, however, been for the most part neglected until recently. In November of last year the Section of the History of Medicine of the Royal Society of Medicine celebrated its centenary; and the President of the Society, in his introductory address, emphasized the true value and importance of history to the student of medicine. This, as he reminded us, was fully realized by the first President of this Section, Sir William Osler, in 1912. Since then the history of medicine has gradually attracted more attention and now is beginning to take its rightful place in our curriculum.

Dr. Gibson's book is a welcome addition to the literature of the subject. He covers a very wide field, giving personal impressions of many distinguished men from the I8th century onwards. His first chapter furnishes a comprehensive account of Baron Larrey, surgeon to Napoleon's armies (r766-1842), of whom comparatively little has hitherto been written, but who is undoubtedly a striking example of the creative mind. Subsequent chapters include neurology, problems in aviation medicine, the study of physical factors in mental disease, and even contributions by medical men to music and to general literature. Not least among the many interesting pages are those devoted to the contributions by medical undergraduates.

The author has cast his net so widely that one might almost say that his book is too inclusive. He has mentioned so many among our profession, some better known than others, that it has only been possible to give a very brief account of the life and work of each of them individually. For the main purpose of the book this is inevitable, and we do not mean this as a criticism. It has, on the other hand, a definite advantage in that it calls attention to a great number of examples of the creative mind that might otherwise have escaped our notice. There is, however, a good index, and appended to each chapter is a list of selected references. With such documentation this volume should prove a good stimulus to further study of medical history and an encouragement to all those who can perceive the value and importance of the creative mind.

\section{An Introduction to Diagnostic Enzymology}

J. H. Wilkinson, PH.D., D.SC., F.R.I.C. Pp. viii + 288, illustrated. London: Edward Arnold. 1962. $45 s$.

As indicated by its title, this book provides an informative introduction to the rapidly expanding field of clinical enzymology. It should be useful to clinical biochemists as much as to medical students and clinicians.

The opening chapter contains an elementary but easily comprehensible description of the fundamental properties of enzymes, coenzymes, activators and inhibitors, and of the essentials of enzyme kinetics. A short chapter follows which is devoted to the localization of diagnostically important enzymes in the body, the treat气 ment of samples intended for enzyme determination and similar topics of importance to the laborator $b$ worker. The next six chapters describe the charace teristics, determination and diagnostic importance of various classes of enzyme, including the digestive enzymes, the phosphatases, transaminases, dehydro $=$ genases, glycolytic enzymes and cholinesterases. Tw chapters deal respectively with enzymes in inborn error홍 of metabolism and with miscellaneous enzymes o $\bar{p}$ diagnostic value and the concluding chapters describథ enzyme tests in myocardial infarction and liver disease and the origin and fate of serum enzymes respectivelyos Useful bibliographies, covering standard works, reviews. and original papers, follow each chapter.

No attempt is made to give detailed descriptions of laboratory methods for enzyme determination, exceptw for eight of the most commonly used methods which appear in an appendix. However, the reader concerne with such details will be able to obtain them withouB. difficulty from the bibliographies, and the outlines of the methods given in the text provide useful guides to the choice of methods.

The text contains some irritating tricks of style, such as the frequent use of the hackneyed word 'cases' wherin the author means 'patients', and there is some un N necessary verbosity which makes reading difficult iá places. These are minor criticisms, however, which dø not detract from the general usefulness of the book? The volume is clearly printed on good-quality pape $\overrightarrow{\vec{r}}$ with an adequate index.

Pathology of the Upper Respiratory Tract

R. E. Rewell, M.D., M.R.C.P. Pp. viii + a illustrated. Edinburgh and London: E. \&cق Livingstone. 1963. 40s.

Monographs on special subjects are tending to replace the standard textbooks of pathology and Dr. Rewell' book is welcome, for ear, nose and throat pathology is particularly inadequately covered in the larger works As consultant pathologist to the E.N.T. Infirmary Liverpool, Dr. Rewell has great experience in this fiel\$ and has condensed nearly Io years' work into his book?

The postgraduate student will probably find the book more useful than the morbid anatomist. Etiology an pathogenesis of most conditions are discussed in detaif but histological descriptions are rather inadequate. This is particularly unfortunate, as the photomicrographs frequently do not compensate for inadequacies in the text. The first two chapters deal with the pathology of the nose and sinuses and include a good account of malignant granulomas of the nose. Following this are chapters on the pharynx and larynx. It is surprising that the author makes no mention of the presence of amyloid material in the laryngeal nodule, which is by n\$ means uncommon and immediately afterwards com을 ments on the rarity of amyloid tumours. Major errors and omissions are very few, however, in this part of tho book.

Exception may be taken to the last three chapters devoted to tumours of lymphoid tissue, salivary gland and skin and bones. Together nearly one-third of the book is occupied by these subjects and most of the topics discussed fall outside those usually included oto-rhino laryngology. In an effort to compress such $\Phi$ vast field into three chapters the author has inevitabl omitted important material; for example, there is no mention of the relationship of toxoplasmosis to histio cytic medullary reticulosis and much of the discussion of leukæmias is almost incomprehensible.

Little would have been lost by omission of thes 